\title{
Microsurgery: The Top 50 Classic Papers in Plastic Surgery: A Citation Analysis
}

\author{
Cormac Weekes Joyce, Sean Michael Carroll \\ Department of Plastic Surgery, St. Vincent's University Hospital, Elm Park, Dubin 4, Ireland
}

Background The number of citations that a published article has received reflects the importance of the paper in the particular area of practice. In microsurgery, thus far, which journal articles are cited most frequently is unknown. The purpose of this study was to identify and analyze the characteristics of the top 50 papers in the field of microsurgery in the plastic surgery literature.

Methods The 50 most cited papers published in high impact plastic surgery and microsurgery journals were identified. The articles were ranked in the order of the number of citations received. These 50 classic papers were analyzed for article type, journal distribution, and geographic and institutional origin.

Results Six international journals contributed to the top 50 papers in microsurgery. The most cited paper reported on the early use of the vascularized bone graft and was cited 116 times. The top 50 papers originated from just 10 countries with the United States producing the most. The Preston and Northcote Community Hospital, Melbourne published 5 papers and this was the most productive institution in the top 50.

Conclusions These papers represent many important milestones in the relatively short history of microsurgery. Furthermore, our citation analysis provides useful information to budding authors as to what makes a paper attain a "classic" status.

Keywords Microsurgery / Bibliometrics / Classical article
Correspondence:

Cormac Weekes Joyce

Department of Plastic Surgery,

St Vincent's University Hospital,

Elm Park, Dublin, Ireland

Tel: $+353-876815514$

Fax: $+353-876815514$

E-mail: cjoyce78@hotmail.com

This article contains supplemental Table S1.

No potential conflict of interest relevant to this article was reported.

\section{INTRODUCTION}

The term "microvascular surgery" was coined by Jules Jacobson in 1960 when he performed the first small vessel repair using a microscope. In 1963, Kleinert et al. [1] performed the first revascularization of a partial digital amputation, but it was not until Taylor and Daniel [2] first reported a free flap transfer using microvascular techniques in 1973, that microsurgery as a subspecialty of plastic and reconstructive surgery, began to evolve. This was attributed in part to a greater understanding of angiosomes [3] coupled with important innovations and technological ad- vancements over the last 40 years. Over the years, a large body of work pertaining to the field of microsurgery has been published, yet it is not known which of these original articles has had the most impact on this field. The relevance of published scientific work to a particular area is reflected in the number of peer citations that it receives. Citations are abbreviated alphanumeric expressions that acknowledge the relevance given by the author to the work of peers on the subject of discussion in which the citation appears. The primary aim of a citation is to give credit to other authors for valuable relevant information that they have previously published. The larger the number of citations a body 
of published work has received, the more reputable its author is thought to be. A large number of citations for a paper are of paramount importance to a journal as well, as the more cited an article from a particular journal is, the greater is the impact factor (IF) of the publication [1]. The IF $[4,5]$ of a journal is a measure used for reflecting the average number of citations to the recent articles published in the journal. It is calculated annually and is utilized as a proxy for the relative importance of an academic journal within its field. The higher the IF, the more important the journal is deemed. It is viewed as the best method of judging the merits of specific journals despite there being problems with the system $[6,7]$. The IF is calculated for a given year, by finding the average number of citations received per article published in that journal during the two preceding years. Citation analysis is a bibliometric process that describes the means of analyzing the citation history of published papers [8].

Several medical and surgical specialties have previously published on the most frequently cited papers relating to their specific field $[8,9]$. The surgical specialties that have done this include general surgery [10], plastic surgery [11], orthopedics $[8,12,13]$, and otolaryngology [14]. An analysis of the classic papers in each of these specialties has created a better understanding of the characteristics required of a piece of research in order for it to receive a sufficient number of citations for it to be recognized as a "classic" paper. To date, there has not been a study evaluating the most cited and relevant papers in the field of microsurgery. We have focused on the most important papers on microsurgery in the plastic surgery literature on the basis of the number of citations that these papers have received.

\section{METHODS}

All microsurgery articles from journals in the plastic surgery and microsurgery literature were included in our search from their

\section{Table 1. Journals included in our bibliometric analysis}

\section{Journal name}

Plastic and Reconstructive Surgery

Journal of Plastic Reconstructive and Aesthetic Surgery

Microsurgery

Journal of Reconstructive Microsurgery

Canadian Journal of Plastic Surgery

British Journal of Plastic Surgery

Annals of Plastic Surgery

Clinics in Plastic Surgery

European Journal of Plastic Surgery

Scandinavian Journal of Plastic and Reconstructive Surgery

Journal of Plastic Surgery and Hand Surgery

Ophthalmic Plastic and Reconstructive Surgery initial year of publication (Table 1). The database of the Science Citation Index of the Institute for Scientific Information was used for identifying the most-cited microsurgery papers from 1945 to 2013 in all of these publications.

By using this database, we identified the 50 most-cited articles relating to microsurgery in the selected journals (Supplemental Table S1). Using a method previously described by Paladugu et al. [10], we analyzed each paper individually by looking at its subject matter, authorship, article type, institution, country and year of publication.

\section{RESULTS}

Thirty-two of the top 50 microsurgery papers have been cited over 200 times. The most-cited paper, by Taylor et al. [15], had a total of 688 citations, whereas the 50th paper on the list had just 168 citations. The most recent paper in the top 50 was from 2004, and it was cited 194 times in total. The oldest paper included was from 1968 and has been cited 190 times to date. Most of the published papers included were from the 1980s (Table 2), and the next most frequent decade within the top 50 was the 1990s. Only six international journals contributed to the top 50 microsurgery papers despite 12 journals being included in our citation search. Plastic and Reconstructive Surgery completely dominated the top 50 and had 37 entries in total (Table 3).

The top 50 classic microsurgery papers in the plastic surgery literature came from 10 countries, with the United States and Australia producing the most (Table 4). Thirty institutions were responsible for producing all of the top 50 papers. Now closed, the Preston and Northcote Community Hospital in Melbourne,

Table 2. Most popular papers cited by decade

\begin{tabular}{|lcc|}
\hline Rank & Decade & No. of papers \\
\hline 1 & 1980 's & 20 \\
2 & 1990 's & 13 \\
3 & 1970 's & 12 \\
4 & 2000 's & 4 \\
5 & 1960 's & 1 \\
\hline
\end{tabular}

Table 3 . The journals which contributed to the top 50 papers

\begin{tabular}{|lc|}
\hline Journal & $\begin{array}{c}\text { No. of papers } \\
\text { in top 50 }\end{array}$ \\
\hline Plastic and Reconstructive Surgery & 37 \\
British Journal of Plastic and Reconstructive Surgery & 7 \\
Annals of Plastic Surgery & 2 \\
Canadian Journal of Plastic Surgery & 2 \\
Microsurgery & 1 \\
Scandinavian Journal of Plastic and Reconstructive Surgery & 1 \\
\hline
\end{tabular}


Table 4. Countries of origin of the top 50 papers in microsurgery

\begin{tabular}{|lc|}
\hline Nation & No. of papers \\
\hline United States & 18 \\
Australia & 11 \\
United Kingdom & 5 \\
Japan & 5 \\
Canada & 3 \\
Taiwan & 3 \\
China & 2 \\
Belgium & 1 \\
Sweden & 1 \\
Yugoslavia & 1 \\
\hline
\end{tabular}

Table $\mathbf{5}$. Institutions most represented by the top $\mathbf{5 0}$ papers in microsurgery

\begin{tabular}{|clc|}
\hline Rank & \multicolumn{1}{c|}{ Institution } & No. of papers \\
\hline 1 & $\begin{array}{l}\text { Preston and Northcote Community Hospital, } \\
\text { Melbourne }\end{array}$ & 5 \\
2 & Royal Melbourne Hospital, Melbourne & 4 \\
3 & Canniesburn Hospital, Glasgow & 3 \\
4 & University of Toronto & 3 \\
5 & University of Texas system & 3 \\
6 & Louisiana State University medical Centre, LA & 2 \\
7 & Chang Gung Memorial Hospital, Taipei, Taiwan & 2 \\
8 & Memorial Sloan Kettering, NY & 2 \\
9 & Plastic surgery Hospital, Beijing & 2 \\
10 & St. Vincent's Hospital, Melbourne & 2 \\
11 & University of California, San Francisco & 2 \\
\hline
\end{tabular}

Australia, produced five papers in total. Eleven institutions had two or more papers in the top 50 (Table 5).

Of the 50 "classic" papers, 40 reported on clinical experience, 8 were anatomical studies, 1 was a basic science paper, and 1 was a case report. Thirty-eight papers reported on free tissue transfer and microvascular anastomoses. Four papers reported on nerve healing and microneural repair. Seven authors wrote more than one paper in the most-cited list of microsurgery papers (Table 6). Dr. Taylor was the first author on seven separate papers, while Dr. Wei wrote three papers.

The most-cited paper on our list was by Taylor et al. [15]; it documents the early use of a free vascularized bone graft and had 116 more citations than the second most-cited paper, which was another paper by Taylor in which the term "angiosome" was first coined. This seminal paper remains highly regarded as it provides valuable information on the various vascular territories of the body. The third most-cited paper was by Hidalgo [16] in which he first described the free fibula flap for the reconstruction of the mandible. This paper is more than 20 years old, yet this technique remains extremely popular for mandibular reconstruction. Godina [17]'s landmark paper on the microsurgical recon-
Table 6. The first-name authors who had more than one of their papers in the most-cited papers

\begin{tabular}{|clc|}
\hline Rank & Author & No. of first-name papers \\
\hline 1 & Taylor Gl & 7 \\
2 & Wei FC & 3 \\
3 & Soutar DS & 2 \\
4 & Khouri RK & 2 \\
5 & Hidalgo DA & 2 \\
6 & Koshima I & 2 \\
7 & Mathes SJ & 2 \\
\hline
\end{tabular}

struction of the extremities has been cited 455 times to date and remains as one of the most well-known papers in the field of microsurgery. Breast reconstruction utilizing the deep inferior epigastric perforator (DIEP) flap was described by Allen and Treece [18] in 1994, and this was the sixth most-cited paper in the top 50. The classification of the vascular anatomy of muscles was described in 1981 by Mathes and Nahai [19], and the importance of this paper is reflected in the fact that their classification system is still found in most plastic surgery textbooks today. The first description of the free omental flap for scalp defect reconstruction by McLean and Buncke [20] is at number 25, while Blondeel [21] reports on his experience of 100 free DIEP flaps for breast reconstruction in the paper ranked 26th. The oldest paper was a case report, cited 190 times; it describes the successful replantation of an amputated thumb. The landmark 1984 paper by Taylor et al. [22] at 43, which was cited 186 times, reported on the versatility of the deep inferior epigastric flap. At 47, the 1973 paper by O'Brien et al. [23] reported on the microvascular transfer of a groin island flap to the foot.

\section{DISCUSSION}

This list of classic papers in the field of microsurgery in the plastic surgery literature provides us with valuable information as to the authors and topics that have had a profound influence on this discipline. The larger the number of times a paper is cited in other articles, the greater is the IF of the journal. Furthermore, the number of citations is used for assessing the impact that the individual author has made in that particular area.

By analyzing the Science Citation Index of the Institute for Scientific Information, we could identify the most-cited papers in the field of microsurgery. These represent the most influential papers that had the greatest impact on their peers in this specialty. By browsing through the 50 most-cited papers, it is difficult not to appreciate the seminal papers that are present. These papers represent many of the important milestones that have occurred in the field of microsurgery over the last 45 years. However, the 
specialty of microsurgery has produced many classic papers that are not found in this list. The phenomenon of "obliteration by incorporation" may account for this, as over time, many "classic papers" may have become such common knowledge that they are deemed not necessary to cite. This indicates that the number of citations a paper has received should not reflect its overall importance to the field of microsurgery historically. It has been suggested that the most important landmark papers in the field of microsurgery can be located in the reference list of the most-cited papers [10]. In contrast, it has been reported that the older the articles are, the greater is the likelihood that they have attained more citations purely because their citable period was longer [11].

Examining the list of the top 50 most-cited papers gives us an insight into the history and development of microsurgery over the past four decades. We have identified the seminal papers that have been responsible for the most significant impact on the field of microsurgery. The United States has contributed a majority of papers to the list and led the rankings in the output of publications in all 20 scientific disciplines according to the Institute of Scientific Information [6,7]. However, it has been demonstrated that authors from the United States tend to have biased citation practices [24]. Further, it has been reported that American reviewers have a bias towards American papers [25]. Interestingly, 13 papers in the top 50 came from countries where English is not the first language (Japan, Taiwan, Sweden, China, Belgium, Sweden, and Yugoslavia). The remaining papers came from English-speaking countries (the United States, the United Kingdom, Canada, and Australia).

However, there are certain limitations of this type of study. "Incomplete citing" occurs when references are made in order to persuade the reader rather than to give credit to those who most influenced their work. In the field of microsurgery, there have been frequently cited papers published that have appeared outside of the journals that we included in our citation search. A good example of this would be a paper published in Archives of Otolaryngology-Head and Neck Surgery by Urken et al., which has been cited 207 times to date. This article reported on the authors' experience of 200 microvascular free flaps in head and neck surgery. For our study, we decided to omit papers from otolaryngology, ophthalmology and orthopedic journals, and to focus solely on the most-cited microsurgery articles in the field of plastic surgery. Other biases that occur in our type of study include in-house bias; journal bias; self-citation; powerful person bias; parochialism by country, state, or institution; language bias towards the English language; and omission bias by purposely not citing competitors [6,7]. Despite these biases, the top 50 most-cited papers in the field of microsurgery are a good rep- resentation of some of the most important works over the last 40 years, and each paper should be regarded as having attained "classic" status on the basis of citation numbers alone. The list of top 50 microsurgery papers in the plastic surgery literature is useful for several reasons, as it identifies the landmark papers that have contributed greatly to the specialty. It also allows us to see which institutions and authors have contributed to these and have subsequently led the way in the field of microsurgery and research. Furthermore, it provides useful information to authors as to what it entails to write a "classic paper." To produce such a body of work, a novel idea, innovation, or observation must be found that has an enduring effect on the way we practice microsurgery. Our results have shown that the paper should ideally be published in the English language and in a journal with a high IF. We have also observed that it would more likely to be published if it originates from the United States.

The measurement of scientific quality is not based on citation analysis. However, the more times a paper has been cited does reflect the importance and impact that the article has had on the scientific community as a whole. The "classic papers" in the field of microsurgery that we have considered in this study are the ones that have had the greatest impact on the microsurgical community and are more than likely the ones that will be remembered the most.

\section{REFERENCES}

1. Kleinert HE, Kasdan ML, Romero JL. Small blood-vessel anastomosis for salvage of severely injured upper extremity. J Bone Joint Surg Am 1963;45:788-96.

2. Taylor GI, Daniel RK. The free flap: composite tissue transfer by vascular anastomosis. Aust N Z J Surg 1973;43:1-3.

3. Taylor GI, Palmer JH. The vascular territories (angiosomes) of the body: experimental study and clinical applications. $\mathrm{Br}$ J Plast Surg 1987;40:113-41.

4. Garfield E. The impact factor and its rightful use. Anaesthesist 1998;47:439-40.

5. Garfield E. Journal impact factor: a brief review. CMAJ 1999; 161:979-80.

6. Seglen PO. Why the impact factor of journals should not be used for evaluating research. BMJ 1997;314:498-502.

7. Kelly JC, Glynn RW, O’Briain DE, et al. The 100 classic papers of orthopaedic surgery: a bibliometric analysis. J Bone Joint Surg Br 2010;92:1338-43.

8. Baltussen A, Kindler $\mathrm{CH}$. Citation classics in anesthetic journals. Anesth Analg 2004;98:443-51.

9. Dubin D, Hafner AW, Arndt KA. Citation classics in clinical dermatologic journals. Citation analysis, biomedical journals, 
and landmark articles, 1945-1990. Arch Dermatol 1993;129: 1121-9.

10. Paladugu R, Schein M, Gardezi S, et al. One hundred citation classics in general surgical journals. World J Surg 2002; 26:1099-105.

11. Loonen MP, Hage JJ, Kon M. Plastic Surgery Classics: characteristics of 50 top-cited articles in four Plastic Surgery Journals since 1946. Plast Reconstr Surg 2008;121:320e-7e.

12. Bosker BH, Verheyen CC. The international rank order of publications in major clinical orthopaedic journals from 2000 to 2004. J Bone Joint Surg Br 2006;88:156-8.

13. Mehlman CT, Wenger DR. The top 25 at 25: citation classics in the Journal of Pediatric Orthopaedics. J Pediatr Orthop 2006;26:691-4.

14. Fenton JE, Roy D, Hughes JP, et al. A century of citation classics in otolaryngology-head and neck Surgery journals. J Laryngol Otol 2002;116:494-8.

15. Taylor GI, Miller GD, Ham FJ. The free vascularized bone graft. A clinical extension of microvascular techniques. Plast Reconstr Surg 1975;55:533-44.

16. Hidalgo DA. Fibula free flap: a new method of mandible reconstruction. Plast Reconstr Surg 1989;84:71-9.

17. Godina M. Early microsurgical reconstruction of complex trauma of the extremities. Plast Reconstr Surg 1986;78:285-92.

18. Allen RJ, Treece P. Deep inferior epigastric perforator flap for breast reconstruction. Ann Plast Surg 1994;32:32-8.

19. Mathes SJ, Nahai F. Classification of the vascular anatomy of muscles: experimental and clinical correlation. Plast Reconstr Surg 1981;67:177-87.

20. McLean DH, Buncke HJ Jr. Autotransplant of omentum to a large scalp defect, with microsurgical revascularization. Plast Reconstr Surg 1972;49:268-74.

21. Blondeel PN. One hundred free DIEP flap breast reconstructions: a personal experience. Br J Plast Surg 1999;52: 104-11.

22. Taylor GI, Corlett RJ, Boyd JB. The versatile deep inferior epigastric (inferior rectus abdominis) flap. Br J Plast Surg 1984;37:330-50.

23. O’Brien BM, MacLeod AM, Hayhurst JW, et al. Successful transfer of a large island flap from the groin to the foot by microvascular anastomoses. Plast Reconstr Surg 1973;52:271-8.

24. Campbell FM. National bias: a comparison of citation practices by health professionals. Bull Med Libr Assoc 1990;78: 376-82.

25. Link AM. US and non-US submissions: an analysis of reviewer bias. JAMA 1998;280:246-7.

Supplemental Table S1. The 50 most-cited microsurgery articles in plastic surgery

Supplemental data can be found at: http://e-aps.org/src/sm/aps-41-153-s001.pdf 